\title{
Which One Is More Important For The Diagnosis Of Acute Pancreatitis? Blood Tests Or Imaging?
}

\author{
* Cesareddin Dikmetaş*, Başar Cander, *,Bensu Bulut, *Dilek Atik, *Ayla Köksal, *Ramazan Güven \\ *University of Health Science, Kanuni Sultan Suleyman Training and Research Hospital, Department of \\ Emergency Medicine, Istanbul, Turkey
}

doi.org/10.33706/jemcr.566729

\begin{abstract}
Introduction: Acute pancreatitis (AP); It is defined as a reversible inflammatory process in which the tissue of the pancreas is affected at various degrees, accompanied by local tissue or organ systems. We report the case with a diagnosis of acute pancreatitis, who have abdominal pain; but no serum amylase and lipase elevation. We diagnosed edematous pancreatitis image in the computed tomography (CT).
\end{abstract}

Case: A 51-year-old male admitted to the emergency department(ED) with sever abdominal pain. He had diabetes mellitus (DM) in his medical history. His vital signs were normal. He has epigastric tenderness, abdominal guarding on palpation; no rebound tenderness or rigitidy was noted. The blood test measurements were WBC: $5.5010^{3} / \mathrm{uL}$, Glucose: $444 \mathrm{mg} / \mathrm{dl}, \mathrm{AST}: 13 \mathrm{U} / \mathrm{L}$, ALT: $15 \mathrm{U} / \mathrm{L}$, GGT:33 U/L, ALP: 107 U/L, Amylase: 28: U/L, Lipase: 58.8 U/L, CRP: 104.05 mg/L. In abdominal ultrasonography of the patient; pancreas and midline structures could not be evaluated due to gas. No ultrasonographic pathology was detected in other intraabdominal organs. Contrast-enhanced CT of the abdomen was performed because of persistant, severe abdominal pain and it revealed peripancreatic diffuse inflammatory densities (edematous pancreatitis), shown in image 1. The patient was consulted with the internal medicine clinic.Internal Medicine Clinic suggested hospitalization with the diagnosis of edematous pancreatitis to him.

Conclusion: As in this case, blood tests are not sufficient for diagnosis of pancreatitis and if there is clinical necessity, the emergency physician should consider imaging examinations for diagnosis of pancreatitis.

Keywords: Abdominal Pain,Pancreatitis,Amylase,Lipase

\section{Introduction}

Acute pancreatitis (AP) is identified as a reversible inflammatory process which affects the pancreatic tissue by different grades accompanied by local tissue and organ systems (1, 2). The condition is characterized by clinical manifestations including upper abdominal pain with sudden onset and concomitant vomiting, fever, tachycardia, leukocytosis (3), 3-fold increase in amylase and lipase levels in the serum (4-5). Acute pancreatitis has a wide disease spectrum varying from a self-limiting disease with significant abdominal pain to severe fluid loss, metabolic imbalance, hypotension, sepsis and death. Mortality rate after acute pancreatitis was reported as $6 \%$ to $23 \%$ in different series $(6,7)$. We present a case who referred because of abdominal pain and do 
not have elevation in serum amylase and lipase levels; and diagnosed with edematous pancreatitis in computed tomography.

\section{Case Report}

A 51-year old male patient referred to emergency clinic because of abdominal pain. Since the patient and his relative are foreign, an exact communication could not be established; however, the patient mentioned a severe abdominal pain and he showed the epigastric region where the pain is severe. As much as learned, the patient had diabetes mellitus in his history; however, the medications which are regularly used could not be learned.

The following findings were obtained during physical examination at referral to the emergency clinic; overall state was well, arterial blood pressure was $130 / 90 \mathrm{mmHg}$, pulse was $100 / \mathrm{min}$, body temperature was $36.5^{\circ} \mathrm{C}$. Abdominal examination revealed defense $(+)$, rebound $(-)$ and epigastric tenderness $(+)$. There was not any pathological finding in examination of the respiratory system, cardiovascular system and neurological examination.

Blood tests were as follows; WBC: 5.50 103/uL, Hb:13.2 g/dl, PIt:160.000 103/uL, Glucose: $444 \mathrm{mg} / \mathrm{dl}$, urea:30.0 mg/dl, creatinine: $0.74 \mathrm{mg} / \mathrm{dL}$, AST: $13 \mathrm{U} / \mathrm{L}$, ,ALT: 15 U/L, GGT:33 U/L, ALP: 107 U/L, Amylase: 28: U/L, Lipase: $58.8 \mathrm{U} / \mathrm{L}$, CRP: $104.05 \mathrm{mg} / \mathrm{L}$ Troponin: $0.006 \mathrm{ng} / \mathrm{ml}$. ECG was normal at sinus rhythm. Whole abdominal ultrasound scan of pancreas and midline formations was not optimum due to gas. There was not any pathology and intraabdominal fluid in the ultrasound scan of other intraabdominal organs. Due to severe abdominal pain of the patients, Computed Tomography by intravenous contrast was taken. CT scan revealed peripancreatic diffuse inflammatory densities (edematous pancreatitis) (Figure1). Internal diseases department was consulted. Internal Diseases department recommended hydration by intravenous physiological saline and re-consultation with blood tests. Hydration treatment was performed according to the recommendations of the internal medicine department; secondary blood tests were as follows; $5.7510^{3} / \mathrm{uL}$, Hb:13 g/dl, Plt:150.000 103/uL, Glucose: 248 $\mathrm{mg} / \mathrm{dl}$, urea: $18.0 \mathrm{mg} / \mathrm{dl}$, creatinine: $0.6 \mathrm{mg} / \mathrm{dL}$, AST: 12U/L,,ALT: 14 U/L, GGT:31 U/L, ALP: $96 \mathrm{U} / \mathrm{L}$, Amylase: 20: U/L, Lipase: $38.1 \mathrm{U} / \mathrm{L}$, CRP: $120.56 \mathrm{mg} / \mathrm{L}$ Troponin: $0.006 \mathrm{ng} / \mathrm{ml}$. A re-consultation was performed with internal medicine department. Internal diseases department recommended admission by diagnosis of edematous pancreatitis; however, the patient was foreign and he had no medical insurance; and he left the hospital by rejecting the admission and undertaking all risks.

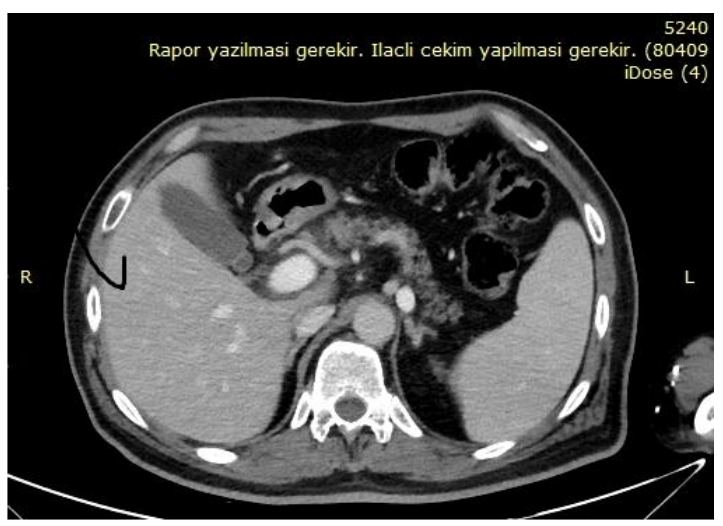

FIGURE 1. CT views of patient's pancreas

\section{Discussion}

Clinical symptoms and findings may differ due to age and severity of the attack in acute pancreatitis (8). Abdominal pain with sudden onset, nausea, vomiting, abdominalş distention are common symptoms and findings $(9,10)$. Although communication problem is experienced in the presented case, he referred to emergency clinic because of abdominal pain with sudden onset and he had epigastric tenderness in the physical exam. The pain is usually severe; however, it is not directly propotional to disease severity (11). The present case had a severe abdominal pain; however, blood tests were nonspecific. Amylase increases to a peak level within first 12 to 24 hours of pancreatitis, and then it decreases to normal levels within 4 to 7 days. Amylase level over $1,000 \mathrm{IU}$ is accepted as diagnostic for acute pancreatitis (12). The present case presented 
normal amylase levels at referral and during follow-up; however, further eleveation could not be detected because the patient has not accepted hospitalization. Demirci et al. reported a case with pancreatitis due to hypertriglycemia who had normal amylase levels in first blood test (3). Since our cas ehas not accepted to be hospitalized, etiology of pancreatitis could not be searched. However, normal amylase levels in first blood tests do not exclude diagnosis of pancreatitis as is seen in the present case. Normal amylase levels in the blood tests of the present case recall the question to what extent we should rely on blood tests to diagnose acute pancreatitis and if imaging should come to forefront; therefore, emergency medicine physicians should notice that pancreatitis cannot be excluded in case of normal amylase levels in the blood tests. Lipase; advanced increase of blood lipase level is accepted as patognomonic for pancreatitis (12). Higher lipase levels were diagnostic; however, sensitivity of lipase is $85 \%$ to $100 \%$ (13) and lower lipase levels were also detected. In such case, like our case, pancreatitis cannot be excluded in normal blood tests during diagnosis of acute pencratitis.

\section{Conclusion}

As presented in this case, acute pancreatitis may be diagnosed rarely even amylase and lipase levels were within normal levels. The emergency medicine physician should evaluate the patient with symptoms and physical examination; and consider imaging techniques towards the diagnosis without relying on blood tests.

\section{REFERENCES}

1.Bradley EL 3rd. A clinically based classification system for acute pancreatitis. Summary of the International Symposium on Acute Pancreatitis, Atlanta, GA, September 11 through 13, 1992. Arch Surg 1993;128:586-90.

2.Carroll JK, Herrick B, Gipson T, Lee SP. Acute pancreatitis: diagnosis, prognosis, and treatment. Am Fam Physician 2007;75:1513-20.

3.Demirci H, Polat Z, Kantarcıoğlu M, Öztürk K, Sakin YS, Uygun A, Bağcı S. An Atypical Presentation in Acute Pancreatitis: Normal Amylase Level. Ankara Med J, 2014, 14 (Annex 1): 1 - 2

4.Al- Bahrani AZ, Ammori BJ. Clinical laboratory assessment of acute pancreatitis. Clinica Chimica Acta 2005; 362:26-48.

5.Byrne MF, Mitchell RM, Stiffler H, Jowell PS, Branch MS, Pappas TN, et al. Extensive investigation of patients with mild elevations of serum amylase and/or lipase is "low yield". Can J Gastroenterol 2002;16: 849-54.

6.Lillemoe KD, Yeo CJ, Management of complications of pancreatitis. Current Problems in Surgery, 1 (1): 1- 98, 1998.

7.Levant JA, Secrist DM, Resin H, et al. Nasogastric suction in the treatment of alcoholic pancreatitis: a controlled study. JAMA 229: 51, 1974.

8.Tamer et al. Evaluation of Acute Pancreatitis Sakaryamj;2011(1):17-21

9.Mitchell RM, Byrne MF, Baillie J. Pancreatitis.Lancet 2003; 361: 1447-55.

10.Koizumi M, Takada T, Kawarada Y, Hirata K, Mayumi T, Yoshida M, et al. JPN Guidelines for the management of acute pancreatitis: diagnostic criteria for acute pancreatitis. J Hepatobiliary Pancreat Surg. 2006; 13:25-32.

11.Vissers RJ, Abu-Laban RB. Acute and chronic pancreatitis. In: Tintinalli JE, Kelen GD, Stapczynski JS (eds.), Emergency medicine. A comprehensive study guide. 5th edition, New York: McGraw-Hill, 2000: 588-592.

12.Pekmezci S. Approach and Treatment in Acute Pancreatitis. I.U. Cerrahpasa faculty of Medicine, Continuous Medical Training Activities Hepato-Biliary System and Pancreatic Diseases Symposium Series No: January, 28, 2002; p. 239-262

13.Agarwal N, Pitchumoni CS, Sivaprasad AV. Evaluating tests for acute pancreatitis. Am J Gastroenterol. 1990;85(4):356.

Funding: None Declared

Conflict of Interest: None Declared

Corresponding Author: Cesareddin Dikmetaş, MD, Specialist in Emergency Medicine, University of Health Science, Kanuni Sultan Suleyman Training and Research Hospital, Department of Emergency Medicine, 34303 Kucukcekmece - ISTANBUL, TURKEY. drcesareddindikmetas@gmail.com 